\title{
The impact of childhood varicella vaccination on the incidence of herpes zoster in the general population: modelling the effect of exogenous and endogenous varicella-zoster virus immunity boosting
}

\author{
Christophe Sauboin ${ }^{1 *+} \mathbb{D}$, Katsiaryna Holl ${ }^{1,{ }^{8}}$, Paolo Bonanni ${ }^{2}$, Anne A. Gershon ${ }^{3}$, Bernd Benninghoff ${ }^{4}$,
} Stephane Carryn ${ }^{5}$, Margaret A. Burgess ${ }^{6}$ and Peter Wutzler ${ }^{7}$

\begin{abstract}
Background: A controversy exists about the potential effect of childhood varicella vaccination on Herpes Zoster $(\mathrm{HZ})$ incidence. Mathematical models projected temporary $\mathrm{HZ}$ incidence increase after vaccine introduction that was not confirmed by real-world evidence. These models assume that absence of contacts with infected children would prevent exogenous boosting of Varicella-Zoster-Virus (VZV) immunity and they do not include an endogenous VZV immunity-boosting mechanism following asymptomatic VZV reactivation. This study aims to explore the effect of various assumptions on exogenous and endogenous VZV immunity-boosting on $\mathrm{HZ}$ incidence in the general population after introduction of routine childhood varicella vaccination.

Methods: An age-structured dynamic transmission model was adapted and fitted to the seroprevalence of varicella in France in absence of vaccination using the empirical contact matrix. A two-dose childhood varicella vaccination schedule was introduced at 12 and 18 months. Vaccine efficacy was assumed at 65\%/95\% (dose 1/dose 2), and coverage at 90\%/80\% (dose 1/dose 2). Exogenous boosting intensity was based on assumptions regarding HZimmunity duration, age-dependent boosting effect, and $\mathrm{HZ}$ reactivation rates fitted to observed $\mathrm{HZ}$ incidence. Endogenous boosting was the same as pre-vaccination exogenous boosting but constant over time, whilst exogenous boosting depended on the force of infection. Five scenarios were tested with different weightings of exogenous (Exo) - endogenous (Endo) boosting: 100\%Exo-0\%Endo, 75\%Exo-25\%Endo, 50\%Exo-50\%Endo, 25\%Exo-75\%Endo, 0\%Exo-100\%Endo.
\end{abstract}

Results: $\mathrm{HZ}$ incidence before varicella vaccination, all ages combined, was estimated at 3.96 per 1000 person-years; it decreased by $64 \%$ by year 80 post vaccine introduction, for all boosting assumptions. The $100 \%$ Exo-0\%Endo boosting scenario, predicted an increase in $\mathrm{HZ}$ incidence for the first 21 years post vaccine introduction with a maximum increase of 3.7\% (4.1/1000) at year 9. However, with 0\%Exo-100\%Endo boosting scenario an immediate $\mathrm{HZ}$ decline was projected. The maximum $\mathrm{HZ}$ incidence increases at 10, 3, and 2 years post vaccination were $1.8 \%$ (75\%Exo-25\%Endo), 0.8\% (50\%EXo-50\%Endo) and 0.2\% (25\%EXo-75\%Endo), respectively.

\footnotetext{
* Correspondence: christophe.j.sauboin@gsk.com

${ }^{\dagger}$ Christophe Sauboin and Katsiaryna Holl contributed equally to this work.

${ }^{1}$ GSK Vaccines, Value Evidence, Wavre, Belgium

Full list of author information is available at the end of the article
}

(c) The Author(s). 2019 Open Access This article is distributed under the terms of the Creative Commons Attribution 4.0 International License (http://creativecommons.org/licenses/by/4.0/), which permits unrestricted use, distribution, and reproduction in any medium, provided you give appropriate credit to the original author(s) and the source, provide a link to the Creative Commons license, and indicate if changes were made. The Creative Commons Public Domain Dedication waiver (http://creativecommons.org/publicdomain/zero/1.0/) applies to the data made available in this article, unless otherwise stated. 
(Continued from previous page)

Conclusions: Assuming modest levels of endogenous boosting, the increase in $\mathrm{HZ}$ incidence following childhood varicella vaccination was smaller and lasted for a shorter period compared with 100\%Exo-0\%Endo boosting assumption. Endogenous boosting mechanism could partly explain the divergence between previous $\mathrm{HZ}$-incidence projections and real-world evidence.

Keywords: Boosting, Varicella, Herpes zoster, Vaccination, Viral infection,

\section{Background}

Varicella (chickenpox) is a highly contagious infectious disease with a peak incidence among preschool and school-aged children. It is caused by the varicella-zoster virus (VZV) [1, 2]. After primary infection, VZV remains latent in neural ganglia until potential reactivation. Herpes zoster (HZ), also called shingles, is caused by the symptomatic reactivation of VZV. This reactivation is assumed to be a consequence of age-related decline of immunity in older adults or of a health condition that decreases the immune function such as for immunocompromised individuals [3-5].

Varicella is considered as a self-limiting disease which annually infects a large number of people, mostly children, almost equal to the size of the annual birth cohort in temperate regions. The disease can lead to serious complications in $3 \%$ of cases under 15 years of age and $6 \%$ of cases above 15 years of age in France, including secondary bacterial infections of skin and lungs, sepsis, aseptic meningitis, encephalitis, and Reye syndrome [3, 4, 6]. Severe VZV infections therefore impose a large burden in terms of public health and health care resource utilization, resulting in large economic and societal impact.

The disease burden and the viral transmission of VZV are reduced by the routine use of varicella vaccine in children. Several live attenuated varicella vaccines have been developed, with well-established efficacy and safety profiles $[4,7,8]$. In countries where varicella is an important public health burden, the World Health Organization recommends the introduction of varicella vaccination into the routine childhood immunization program [8]. A significant decline in varicella incidence has been observed in countries where varicella vaccination has been introduced [9-12]. Despite this body of evidence, in some countries, varicella vaccination is not implemented due to concerns that varicella disease would be shifting to older age groups for which complications occur more frequently, and that varicella vaccination may increase $\mathrm{HZ}$ incidence in the older population $[13,14]$. These potential negative effects are not observed in epidemiological data after 2-dose vaccination in the United States where varicella incidence is shown to decrease in all age-groups [15] and no specific impact of varicella vaccination is observed in the older population ( $>65$ years of age) [16].
The potential negative effects of routine childhood varicella vaccination (RVV) on HZ incidence in older population originate from the "exogenous boosting theory", which postulates that individuals susceptible to $\mathrm{HZ}$ coming into contact with VZV-infected children could maintain their cell-mediated immunity (CMI), thereby reducing the risk of reactivation and developing HZ [1719]. The consequence of this theory is that reducing VZV circulation would result in reduction of contacts with infected children and then immunity boosting events for older people who have had varicella in the past. Therefore, these people would experience lower CMI allowing VZV to reactivate. In 2000, using disease transmission models, Brisson et al. applied this immunity-boosting mechanism and predicted an increase in $\mathrm{HZ}$ incidence in older people following the implementation of RVV [20]. In contrast to these model projections, several published studies based on epidemiological data from countries with RVV have not established an association between vaccination and an increase in $\mathrm{HZ}$ incidence [16, 21-33]. A possible reason for the disparity between the mathematical models and the epidemiological data may be due to the role of endogenous boosting, resulting from asymptomatic VZV-reactivation [17, 34], since the early model by Brisson et al. and later models, focused only on exogenous boosting $[20,35,36]$.

The alternative hypothesis of endogenous boosting suggests that internal factors (e. g. stress) can cause asymptomatic VZV reactivation and boost CMI, thus preventing $\mathrm{HZ}[34,37,38]$. Asymptomatic reactivation of VZV has been shown to occur also in immunocompromised and immunocompetent individuals [39, 40]. Although endogenous boosting is likely to occur [41], the extent of its role at the population level and possible interplay with exogenous boosting remains unknown $[41,42]$.

In this study, we aim to explore the impact of childhood varicella vaccination on HZ incidence through scenarios with different relative weighting of both exogenous and endogenous boosting mechanisms. This may be of importance when modelling the public health impact of RVV on HZ.

\section{Methods}

The model we used for this study is an adaptation of the model developed by Ouwens et al. [43] which we 
modified by adding in an endogenous boosting effect. This population model is an age-structured dynamic transmission model (Fig. 1), developed in Matlab (version 2013b), with the same basic structure as the models by Brisson et al. [20, 35]. Our model is fitted to the age-specific VZV antibody seroprevalence from the French population in absence of vaccination and using an empirical contact matrix. The model reproduced varicella incidence with a plausible age-distribution. Agespecific VZV reactivation factors are then fitted to reproduce HZ incidence. Details of the dynamic model for France, the impact of the contact matrix, and exogenous boosting on varicella and zoster disease epidemiology have been previously reported by Ouwens et al. [43].

Briefly, the model structure (Fig. 1) combines varicella disease states as susceptible (S), i.e. not infected; latent or exposed (E), i.e. exposed to the virus but not showing symptoms; infected (I), which means showing symptoms and being infectious; and recovered (R) from the disease (model structure acronym: SEIR). The varicella part is followed by the zoster disease states as susceptible (Sz), infected (Iz), corresponding to symptomatic VZV reactivation, and recovered $(\mathrm{Rz})$ which is a SIR-type model. Decreasing naturally-acquired VZV immunity with time (decreasing rate $\delta$ ) causes recovered varicella patients to become susceptible to zoster, which means a transition from state $\mathrm{R}$ to state $\mathrm{Sz}$, and0020exogenous boosting (g $\lambda(\mathrm{a}))$ partially offsets this effect by triggering the opposite transition from state $\mathrm{Sz}$ to state $\mathrm{R}$. The endogenous boosting $(\mathrm{e}(\mathrm{a}))$, which is a constant for each age a, is included as a transition from state $\mathrm{Sz}$ to state $\mathrm{R}$ in the natural progression part of the model, and from state VSz to state VR in the vaccination arm of the model. A main difference between endogenous and exogenous boosting effects is that the first one is considered constant over time but is varying over age whereas the second one varies over time as a function of the Force of Infection (FOI, $\lambda$ ), which denotes the rate at which susceptible individuals become infected per unit of time or alternatively measures VZV circulation in the population. Overall, in Fig. 1, the normal disease progression (before vaccination) arm is shown in black, and the disease progression in the vaccination arm in red.

The progression from state $\mathrm{R}$ to state $\mathrm{Sz}$; then from state $\mathrm{Sz}$ to state Iz (as a result of VZV-reactivation) depends on three key parameters: (1) immunity duration against $\mathrm{HZ}$ after a varicella infection, (2) the risk of boosting event as a function of age when susceptible to zoster, and (3) VZV reactivation rates.

For the first parameter, the duration of immunity $(1 / \delta)$ against $\mathrm{HZ}$ is unknown. Therefore, fixed values were assumed and tested in sensitivity analyses: 10 years in the base case and values of 2 and 20 years in the scenario analysis. Regarding the second parameter on the risk of

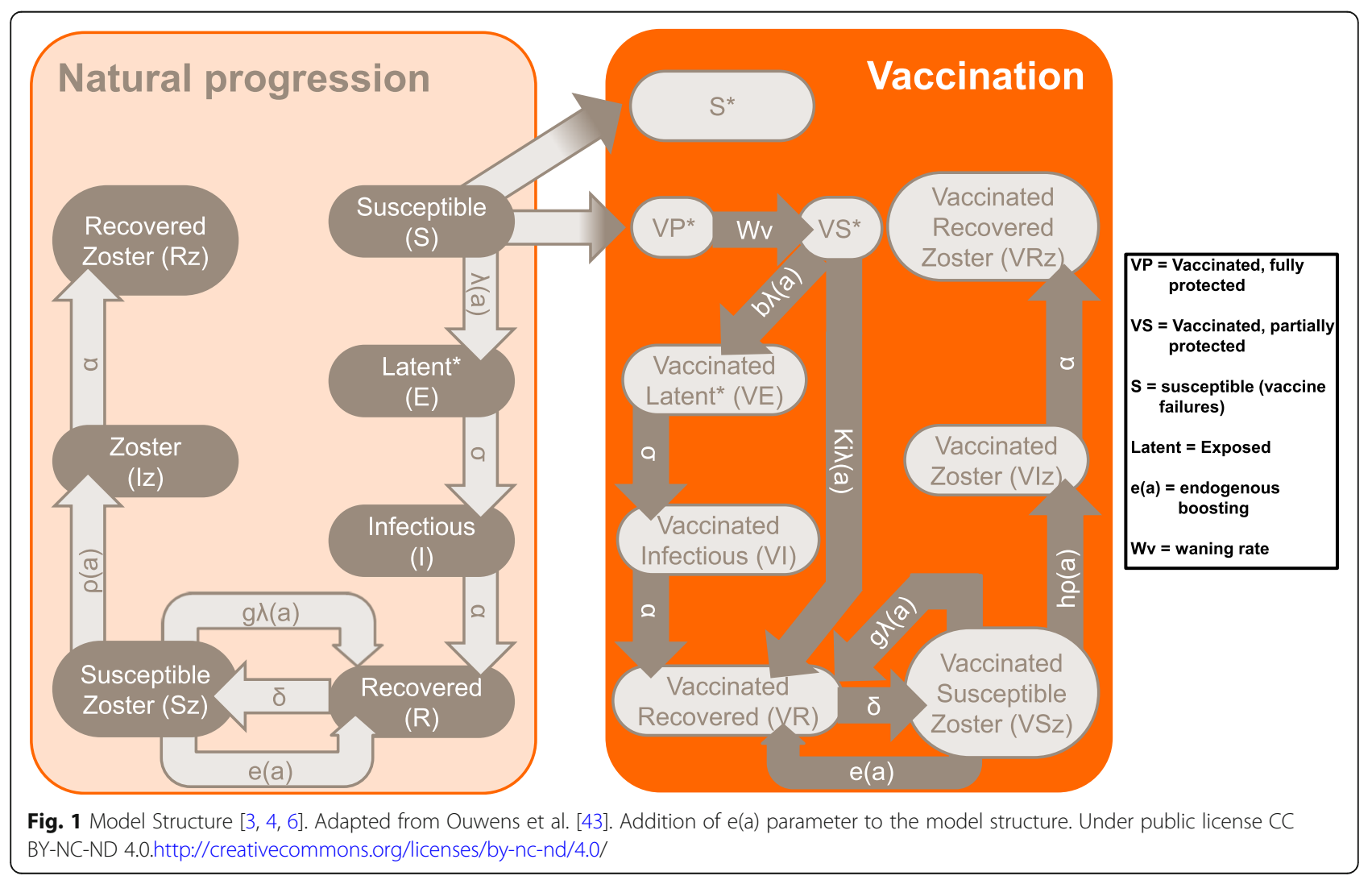


exogenous boosting, the same values are used as in Brisson et al. [35] with a probability of boosting reducing with age from 75 to $50 \%$ after a contact with a varicella infected person (Table 1). Finally, the third parameter relates to the age-specific VZV reactivation rates $(\rho(\mathrm{a}))$ that are calibrated to reproduce HZ incidence (reactivation rates are adjusted accordingly).

Incidence was presented following the French age groups of preschool and school children, young adults, working adults, and older-age population: < 1 year, $1-4$ years, 5-9 years, $10-14$ years, $15-24$ years, $25-44$ years, $45-64$ years, and $\geq 65$ years. The lack of population-level data on endogenous boosting does not allow a full calibration of these parameters. Therefore, the constant age-dependent e(a) was assumed to be the same as the exogenous boosting before vaccination (pre-vaccination equilibrium). This level of boosting was derived by Brisson et al. from results of a trial on the live-attenuated $\mathrm{HZ}$ vaccine efficacy [35, 44].

Five different relative weights of endogenous and exogenous boosting effects were tested as different scena rios in the model (100\%Exo-0\%Endo, 75\%Exo-25\%Endo, 50-\%Exo50\%Endo, 25\%Exo-75\%Endo, and 0\%Exo-100 \%Endo) so that the total force of boosting combining both exogenous and endogenous effects was assumed to be the same before vaccine introduction in all scenarios. In absence of data on the boosting effect, we set the total

Table 1 Model parameters

\begin{tabular}{|c|c|c|c|}
\hline Parameter & Description & Value & Source \\
\hline \multicolumn{4}{|c|}{ Demographic parameters } \\
\hline Birth rate & Fraction of annual birth cohort out of total French population & 0.01295 & INSEE, www.insee.fr [54] \\
\hline \multicolumn{4}{|c|}{ Biological parameters } \\
\hline$\sigma$ & Latent period of varicella (average duration: 14 days) & 26.07 & Brisson et al. [20] \\
\hline a & Infectious period of varicella (average duration: 7 days) & 52.14 & Brisson et al. [20] \\
\hline$\delta$ & Waning natural immunity (average duration: 10 years) & 0.1 & Expert opinion \\
\hline \multirow[t]{4}{*}{$g * \lambda(a)$} & Exogenous boosting against zoster & & Brisson et al. [35] \\
\hline & $<50$ years & $75 \% * \lambda$ & \\
\hline & $50-64$ years & $71 \% * \lambda$ & \\
\hline & $>65$ years & $50 \% * \lambda$ & \\
\hline \multicolumn{4}{|c|}{ Vaccine parameters } \\
\hline mmr1 & $\begin{array}{l}\text { Coverage of first dose of MMR } \\
\text { French current coverage }\end{array}$ & $90 \%$ & \\
\hline $\mathrm{mmr2}$ & $\begin{array}{l}\text { Coverage of second dose of MMR } \\
\text { French current coverage }\end{array}$ & $80 \%$ & \\
\hline Dose1 & Age at first vaccination (in months) & 12 & Assumption \\
\hline Dose2 & Age at second vaccination (in months) & 18 & Assumption \\
\hline $\begin{array}{l}\text { Introduction } \\
\text { time }\end{array}$ & Number of years before maximum vaccination coverage is reached & 3 & Assumption \\
\hline TV & Varicella vaccine efficacy (\% successfully vaccinated and temporarily protected) & $65 \%$ & $\begin{array}{l}\text { Prymula et al. [45]; } \\
\text { NCT00226499 }\end{array}$ \\
\hline P & Varicella vaccine failures (\%) & $5 \%$ & $\begin{array}{l}\text { Prymula et al. [45]; } \\
\text { NCT00226499 }\end{array}$ \\
\hline $1-T v-P$ & Varicella vaccine-recipients partially protected (\%) & $30 \%$ & $100 \%-T v-P$ \\
\hline Wv1 & Waning rate for 1 dose of varicella vaccine (duration 17 years) & 0.0588 & Silverman et al. [55] \\
\hline Wv2 & Waning rate for 2 doses of varicella vaccine (lifelong protection) & $1 e^{-6}$ & Expert opinion \\
\hline $\mathrm{Ki}^{*} \lambda(\mathrm{a})$ & Rate of exogenous boosting & $\begin{array}{l}0.91 * \lambda \\
\text { (a) }\end{array}$ & Brisson et al. [20] \\
\hline h & Relative VZV reactivation after varicella vaccination & 0.167 & Brisson et al. [20] \\
\hline$b * \lambda(a)$ & Rate of infection among vaccinated susceptibles & $\begin{array}{l}0.73 * \lambda \\
\text { (a) }\end{array}$ & Brisson et al. [20] \\
\hline m & $\begin{array}{l}\text { Relative infectiousness of infected vaccine-recipients versus non-vaccine- } \\
\text { recipients }\end{array}$ & 0.5 & Brisson et al. [20] \\
\hline
\end{tabular}

Note: $M M R$ measles, mumps and rubella, MMVR measles, mumps, rubella, and varicella, INSEE National Institute of Statistics and Economic Studies (Institut national de la statistique et des études économiques), VZV varicella zoster virus, WHO World Health Organization 
force of boosting to what was assumed by Brisson et al., [35] i.e. $75 \%$ for people $\leq 50$ years, $71 \%$ for $51-69$ years, $57 \%$ for $70-79$ years and $32 \%$ for $\geq 80$ years.

The model output was the evolution of $\mathrm{HZ}$ incidence over time after childhood varicella vaccine introduction in each scenario.

Tables 1 and 2 present the model input parameters and sensitivity analyses, respectively. Table 2 indicates the vaccination coverage for each dose, time for gradual implementation of varicella vaccination, vaccine efficacy waning assumptions and the type of age-structured contact matrix which is the same as in Ouwens et al. [43]. The table also include the resulting reactivation rates for $\mathrm{HZ}$ obtained after calibration given the assumptions on boosting rate and duration of immunity against HZ (10 years in the base case and 2 to 20 years in the sensitivity analysis). Ageing mechanism was included in the model. Each year, a cohort of newborns is introduced in the population and an age-specific mortality factor was applied while the rest of the population is moved to the older 1-year wide age-group. The mechanism assumed demographic equilibrium (the proportion of each age group remains constant over 100 years). A two-dose childhood varicella vaccination schedule was considered with doses given at the ages of 12 and 18 months.

Vaccine efficacy was obtained from the clinical trials and assumed to be $65 \%$ for the first, and $95 \%$ for the second dose [45]. Vaccine coverages, of $90 \%$ for dose 1 and $80 \%$ for dose 2, were assumed with gradual scaling-up of varicella vaccination coverage over 3 years. No catch-up program was introduced into the model. The last two assumptions are different from Ouwens et al. [43] who have assumed $80 \%$ replacement of measles, mumps and rubella (MMR) by measles, mumps, rubella, and varicella (MMRV), and a $50 \%$ catch-up program.

\section{Results}

HZ incidence was well reproduced by the mathematical model for each age group and all boosting- effect assumptions. Before varicella vaccine introduction, the overall population $\mathrm{HZ}$ incidence was estimated at 3.96 per 1000 individuals, increasing with age (Table 3). Eighty years after varicella vaccine introduction, HZ incidence decreased by approximately 60\% and was consistent across all Exo-Endo scenarios (Table 4). This decrease resulted from the lower risk of developing $\mathrm{HZ}$ in varicella vaccinees as they age. The 100\% exogenous boosting effect and with 10 years of VZV immunity, however, resulted in a temporary initial increase $(3.7 \%)$ in $\mathrm{HZ}$ incidence in the general population for the first 21 years after vaccine introduction (Fig. 2). In contrast, 100\% endogenous boosting resulted in an immediate decrease in $\mathrm{HZ}$ after varicella vaccine introduction.

For the other 3 scenarios (Exo-Endo 75-25\%, Exo-Endo 50-50\%, Exo-Endo 25-75\%), higher proportions of endogenous boosting led to lower temporary increase in $\mathrm{HZ}$ incidence of $1.8,0.8$ and $0.2 \%$ and for shorter duration of increase of 10, 3, 2 years respectively (Table 4).

In addition, higher proportions of endogenous boosting lead to shorter time to maximum temporary increase in HZ incidence: 6 years for 25\%Exo$75 \%$ Endo, 8 years for $50 \%$ Exo-50\%Endo, 9 years for 75\%Exo-25\%Endo.

\section{Sensitivity analysis}

The impact of introducing an endogenous boosting effect on $\mathrm{HZ}$ incidence in the general population was less important with the 2-year VZV immunity scenario, while a substantial difference was observed for 20 years of VZV immunity (Table 4).

Specifically, for $100 \%$ exogenous boosting, with the scenario of 2-year VZV immunity in comparison to the base-case scenario (10 years), the temporary initial increase in $\mathrm{HZ}$ incidence was projected to be smaller (1.3\% versus $3.7 \%$ ) and shorter (3 years versus 21 years). Thus, the estimated impact of increased endogenous boosting effect was smaller in the 2-year immunity scenario than in the base case.

When 20-year VZV immunity was assumed and with $100 \%$ exogenous boosting, the temporary initial increase in $\mathrm{HZ}$ incidence was projected to be higher (5.7\% versus $3.7 \%$ ) and to last longer (33 years versus 21 years) than in the base-case scenario. On the other hand, introducing $25 \%$ of endogenous boosting had a larger impact, with a lower maximum HZ incidence increase $(-3.1$ percentage points, from 5.7 to 2.6\%) and a shorter duration of $\mathrm{HZ}$ incidence compared to pre-vaccination levels ( -10 years from 33 to 23 years).

The maximum estimated increases in $\mathrm{HZ}$ incidence compared to the pre-vaccination rate in the basecase scenario were in the group 25-44 years of age (Fig. 3), although the absolute increase in incidence was larger in the group 45-64 years of age (not shown on the figure). In the scenario with 20 years of $\mathrm{HZ}$ immunity, the maximum increase was projected in the $45-64$ age group. When $50 \%$ Exo-50\%Endo was considered, the maximum temporary initial increase was reduced by $53 \%$ in both the base case and in the 20 -year HZ-immunity scenario, and by $51 \%$ in the 2-year HZ-immunity scenario.

Additional file 1 summarizes the content of the study in a form that could be shared with patients by healthcare professionals. 
Table 2 Base-case and sensitivity analyses

\begin{tabular}{|c|c|c|}
\hline & Description & French coverage \\
\hline \multirow{6}{*}{$\begin{array}{l}\text { Base case } \\
\text { analysis }\end{array}$} & Vaccination coverage of MMR dose 1 and 2 & Dose 1: 90\%; Dose 2: $80 \%$ \\
\hline & Time for replacement (MMR by MMRV) & 3 years \\
\hline & Catch-up program & No catch-up \\
\hline & Exogenous/endogenous boosting & $\begin{array}{l}\text { Included and relative weighting depends on } \\
\text { scenario }\end{array}$ \\
\hline & Contact matrix & Empirical \\
\hline & Vaccine protection & $\begin{array}{l}\text { Post-dose 1: } 17 \text { years; Post-dose 2: lifelong } \\
\text { protection }\end{array}$ \\
\hline \multirow[t]{25}{*}{$\begin{array}{l}\text { Sensitivity } \\
\text { analysis }\end{array}$} & $\begin{array}{l}\text { Waning natural immunity (average duration } 10 \text { years - base case) changed to } 2 \\
\text { and } 20 \text { years }\end{array}$ & $\begin{array}{l}\text { bc: } \delta=0.1 \\
\text { Low: } \delta=0.05 \\
\text { High: } \delta=0.5\end{array}$ \\
\hline & \multicolumn{2}{|l|}{ Reactivation rate of infectious zoster, by age group for $\delta=0.1$} \\
\hline & $0-4$ years & 0.028 \\
\hline & $5-9$ years & 0.009 \\
\hline & 10-14 years & 0.0068 \\
\hline & $15-24$ years & 0.0035 \\
\hline & $25-44$ years & 0.0033 \\
\hline & 45-64 years & 0.008 \\
\hline & $\geq 65+$ years & 0.016 \\
\hline & \multicolumn{2}{|l|}{ Reactivation rate of infectious zoster, by age group for $\delta=0.5$} \\
\hline & $0-4$ years & 0.00769 \\
\hline & $5-9$ years & 0.00339 \\
\hline & 10-14 years & 0.00326 \\
\hline & $15-24$ years & 0.00227 \\
\hline & $25-44$ years & 0.00256 \\
\hline & $45-64$ years & 0.00646 \\
\hline & $\geq 65+$ years & 0.01387 \\
\hline & \multicolumn{2}{|l|}{ Reactivation rate of infectious zoster, by age group for $\delta=0.05$} \\
\hline & $0-4$ years & 0.05478 \\
\hline & $5-9$ years & 0.01666 \\
\hline & 10-14 years & 0.01183 \\
\hline & $15-24$ years & 0.00548 \\
\hline & $25-44$ years & 0.00453 \\
\hline & $45-64$ years & 0.01035 \\
\hline & $\geq 65+$ years & 0.01991 \\
\hline
\end{tabular}

$\delta$, waning natural immunity (average duration 10 years), bc base case (scenario), MMR measles, mumps, and rubella, MMRV measles, mumps, rubella, and varicella

\section{Discussion}

A small number of studies have attempted to model the effect of childhood varicella vaccination on the incidence of $\mathrm{HZ}$ in the population in the presence of endogenous boosting and its relative weight with exogenous boosting. Our analysis shows that even with a limited fraction

Table 3 Pre-vaccination HZ incidence by age group

\begin{tabular}{lccccccc}
\hline All ages & $<5 y$ & $5-9 y$ & $10-14 y$ & $15-24 y$ & $25-44 y$ & $45-64 y$ & $\geq 65 y$ \\
\hline 3.96 & 1.03 & 1.69 & 2.33 & 1.87 & 1.87 & 2.12 & 9.09 \\
\hline
\end{tabular}

$y$ years of age of endogenous boosting, a substantial reduction occurs in the duration and magnitude of temporary initial $\mathrm{HZ}$ incidence increase after introduction of vaccination relative to pre-vaccination levels.

The current insight from the model means that relative weighting of exogenous and endogenous boosting effects may have an important and varied impact on VZV immunity and predicted $\mathrm{HZ}$ burden in the population.

Previous modelling studies projected that RVV would increase $\mathrm{HZ}$ incidence in the general population above 
Table 4 Base-case scenario and sensitivity analysis results

\begin{tabular}{|c|c|c|c|c|c|}
\hline \multirow[t]{2}{*}{$\mathrm{HZ}$ incidence parameters } & \multicolumn{5}{|c|}{ Exogenous-Endogenous (\%) } \\
\hline & $100-0$ & $75-25$ & $50-50$ & $25-75$ & $0-100$ \\
\hline \multicolumn{6}{|l|}{ 2-year immunity to $\mathrm{HZ}$ scenario } \\
\hline Decrease in $\mathrm{HZ}$ by year 80 (\%) & 63.6 & 63.8 & 64.0 & 64.2 & 64.4 \\
\hline Number of years with $\mathrm{HZ}$ increase above pre-vaccine rate & 3 & 3 & 2 & 1 & 0 \\
\hline Max $\mathrm{HZ}$ increase (\%) above pre-vaccine rate & 1.3 & 0.8 & 0.3 & 0.0 & 0.0 \\
\hline Year at max $\mathrm{HZ}$ increase & 3 & 3 & 2 & 2 & NA \\
\hline \multicolumn{6}{|l|}{ 10-year immunity to $\mathrm{HZ}$ scenario (base case) } \\
\hline Decrease in $\mathrm{HZ}$ by year 80 (\%) & 62.1 & 63.1 & 64.0 & 64.8 & 65.6 \\
\hline Number of years with $\mathrm{HZ}$ increase above pre-vaccine rate & 21 & 10 & 3 & 2 & 0 \\
\hline Max HZ increase (\%) above pre-vaccine rate & 3.7 & 1.8 & 0.8 & 0.2 & 0.0 \\
\hline Year at max $\mathrm{HZ}$ increase & 9 & 4 & 3 & 2 & NA \\
\hline \multicolumn{6}{|l|}{ 20-year immunity to $\mathrm{HZ}$ scenario } \\
\hline Decrease in $\mathrm{HZ}$ by year 80 (\%) & 60.1 & 61.8 & 63.3 & 64.7 & 66.0 \\
\hline Number of years with $\mathrm{HZ}$ increase above pre-vaccine rate & 33 & 23 & 9 & 3 & 1 \\
\hline Max HZ increase (\%) above pre-vaccine rate & 5.7 & 2.6 & 1.0 & 0.9 & 0.8 \\
\hline Year at max $\mathrm{HZ}$ increase & 19 & 9 & 1 & 1 & 1 \\
\hline
\end{tabular}

$H Z$ herpes zoster, $N A$ not available

pre-vaccination levels for about 20 to 50 years after the introduction of childhood vaccination under assumption of reduced exogenous boosting [20, 35, 36, 43, 46], and would decrease $\mathrm{HZ}$ incidence after 50 years of RVV. The individual-based dynamic transmission model of Ogunjimi et al. [46] predicted that the increase in $\mathrm{HZ}$ incidence would mainly affect people between 31 and 40 years of age and would decrease over time. Our model predicted a maximum relative increase for the 2544-years age group and was therefore similar to Ogunjimi's finding [46]. However, we found the absolute increase to be higher in the 45-64 years age group. When we compare with real-world data in the United States, despite some long-term increasing trend, epidemiolo

\section{$\mathrm{HZ}$ incidence after V vaccination Base Case}

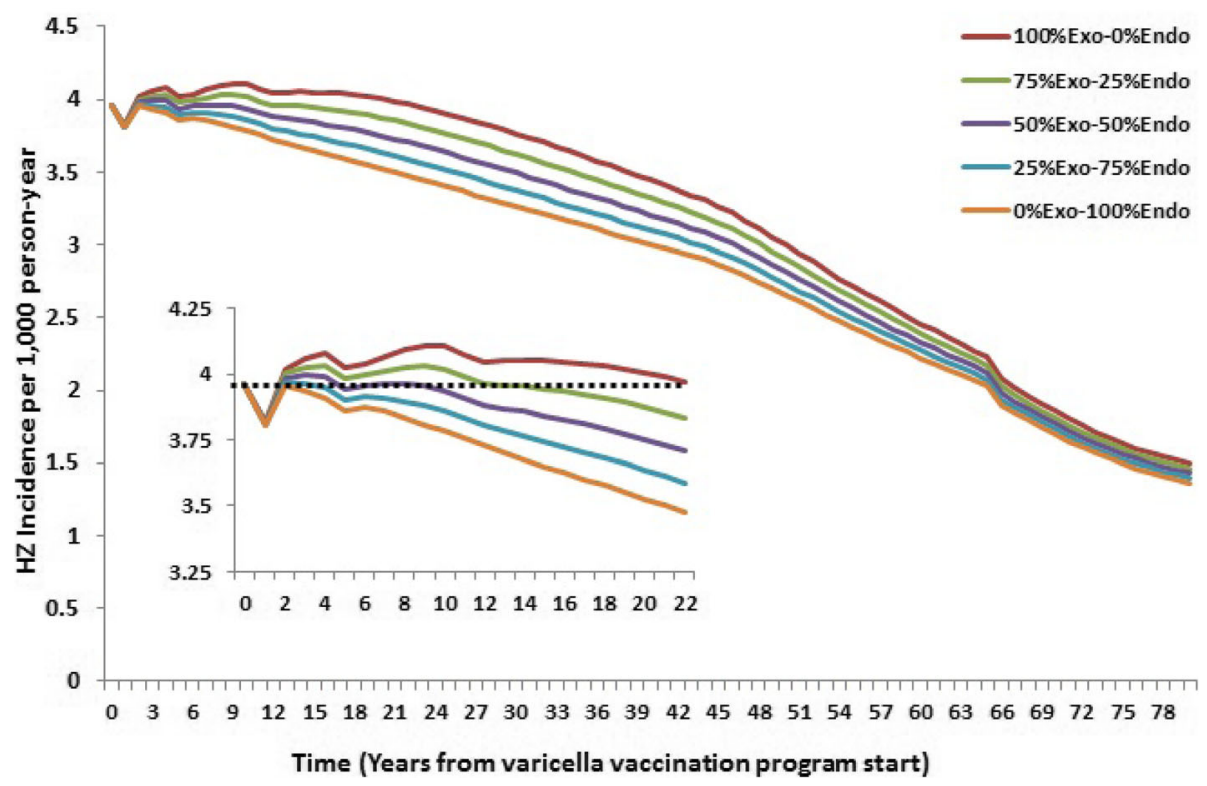

Fig. 2 Trend in post-vaccination $\mathrm{HZ}$ incidence by scenario. $\mathrm{HZ}$, herpes zoster; $\mathrm{V}$, varicella 


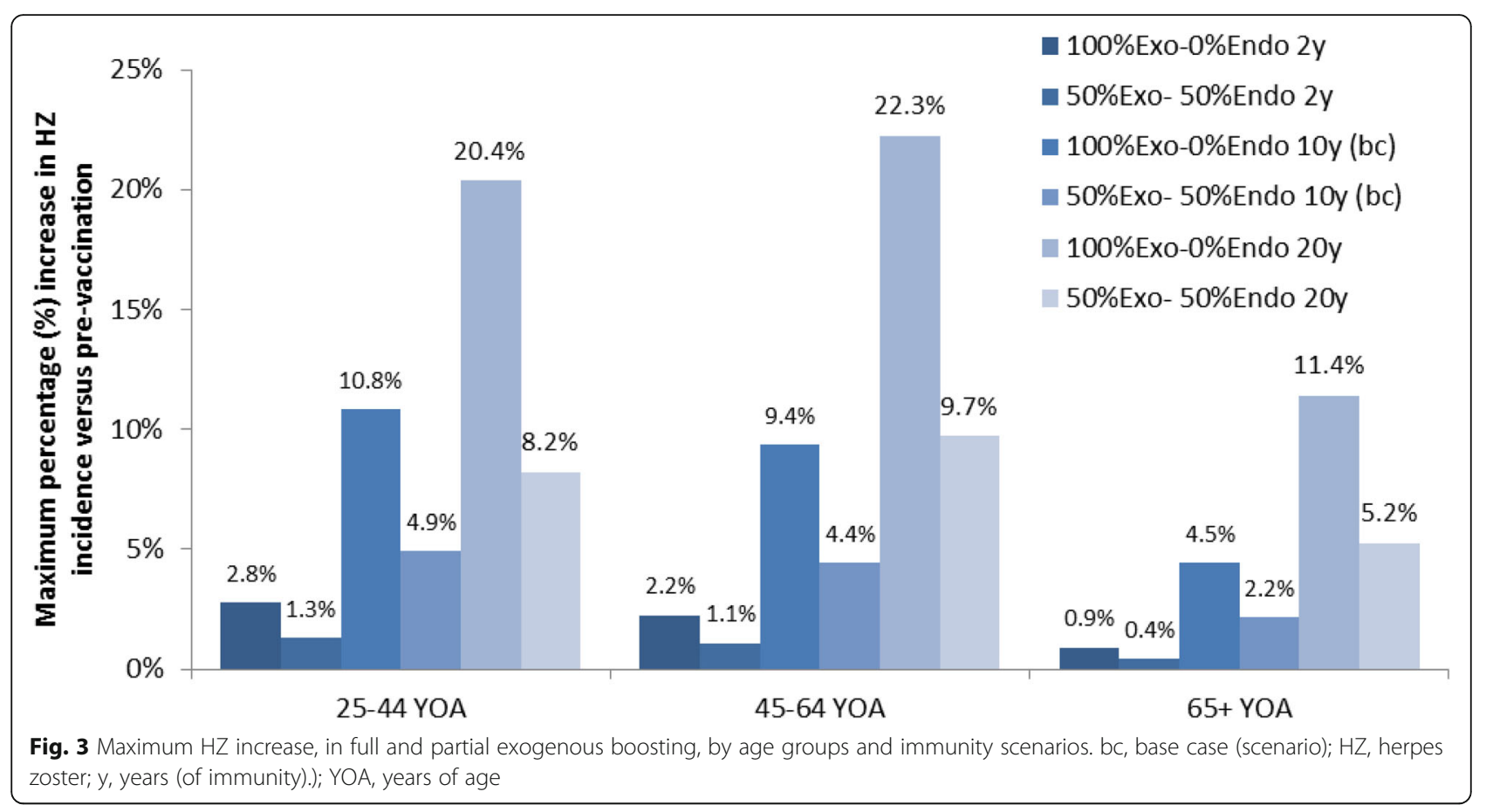

gical data have not shown an increase in HZ incidence related to the introduction of RVV in numerous countries [16, 21-33]. In a cohort study conducted in collaboration with the Centers for Disease Control and Prevention in 8017 patients with HZ, Kawai et al. [32] concluded that the more-than-4-times increase in $\mathrm{HZ}$ incidence over the past 60 years could not be attributed to the introduction of varicella vaccination. They examined the HZ incidence for the periods 1945-1960 and 1980-2007 and found that the incidence of HZ increased at the same rate before and after the introduction of varicella vaccination [32]. A Medicare study also found no association between the increase in $\mathrm{HZ}$ incidence and the introduction of varicella vaccination over 19 years (1992-2010) (relative risk of 0. 9998; 95\% confidence interval, 0. 9997 to 1. 0022) [16]. At the June 2017 Advisory Committee on Immunization Practices meeting, discussions highlighted that none of the United States studies showing an increase in HZ incidence trends, showed evidence of association with varicella vaccination [33]. A recent systematic literature review of $\mathrm{HZ}$ risk reduction through exposure to varicella patients concluded that exogenous boosting exists, but may not be applicable to all situations, and that its magnitude is yet to be determined adequately in future epidemiological studies [34]. Real-world evidence rather suggests that factors other than exogenous, or even endogenous boosting, may play a role in HZ increase in the population, such as the use of immunosuppressive drugs [47]. After revising earlier mathematical models and incorporating recent epidemiological data, another study concluded that generalisations across different countries could not be made, and that the country-specific epidemiology of varicella affects the predicted impact of RVV on HZ [42]. In our modelling study, calibration was performed using only epidemiological data from France, which is a limitation considering that the initial level of exogenous boosting may vary from one country to another. However, some simulations done with data from another country show similar pattern on HZ incidence when introducing endogenous boosting (data not shown).

Using varicella and HZ data from the Netherlands, Marinelli et al. [48], compared the performance of fitting various sets of model parameters based on statistical criteria: Akaike information criterion (AIC) and Bayesian information criterion (BIC). Both criteria modulate the quality of the fit obtained by introducing a penalty on the number of parameters used to fit the data, the penalty being more important for BIC. Interestingly, introducing a constant endogenous boosting rate over age was the best fit for AIC, while excluding endogenous boosting was the best fit for BIC. It should be noted however that a single parameter was used to characterize exogenous boosting across all ages. This implies that the probability of immunity boosting after a contact with a varicella infectious individual is constant over age which is not consistent with previously-published VZV models. Large ranges of HZ-immunity durations have been assumed in the literature (up to 24 years of immunity). In our model, we assumed 10 years of immunity with a variation from 2 to 20 years in the sensitivity analyses. 
Results indicated a similar effect of a shorter 2-year duration of immunity than a longer 10-year immunity with some endogenous boosting. Assuming longer duration of HZ-immunity leads to a larger increase of $\mathrm{HZ}$ incidence after vaccination. In this case, the introduction of endogenous boosting further reduces that negative effect.

Moreover, complex interactions between exogenous and endogenous boosting mechanisms as well as other factors may exist, and the effect on HZ incidence may not be solely influenced by reactivation rates and exogenous boosting, as assumed in dynamic transmission models.

Introduction of $\mathrm{HZ}$ vaccination in older adults [49, 50], alongside the childhood varicella vaccination, could be a strategy to diminish the possible increase in $\mathrm{HZ}$ incidence in the general population. Previous studies that accounted for this approach in their model-based projections anticipated only a small effect of adult $\mathrm{HZ}$ vaccination on the predicted increase in $\mathrm{HZ}$ incidence in persons not vaccinated against varicella $[36,51]$. However, this impact could increase substantially, depending on the effectiveness and duration of protection of the $\mathrm{HZ}$ vaccine as well as acceptance of the community to get a $\mathrm{HZ}$ vaccine [36].

Our study has limitations. The various assumptions (e.g. age at vaccination, vaccine coverage, duration of protection against $\mathrm{HZ}$, and magnitude of exogenous and endogenous boosting), and the uncertainties around these assumptions can have a significant impact on model-based projections.

Some key parameters of the model like vaccination coverage, detection rate of $\mathrm{HZ}$, demography and agestructured contact pattern are based on current knowledge and held constant over the analysis period. These are common hypotheses for population models in high-income countries. Also, due to the compartmental structure of the model, as opposed to individual-based models, heterogeneity in the immune-system status of individuals of the same age is not taken into account. Differences in HZ risk have been reported for different groups in the population e.g., higher risk in female, lower risk for black individuals [52]. Our model does not account for these differences within the population because we ignore if this reflects differences in boosting effect or another mechanism. Varicella disease seasonality was also not included in our model, first because the time-span of the model is long and is not likely to be affected by seasonality, second because it would increase the complexity of the calibration without enhancing the scientific question. HZ-related seasonality has not been established [53]. It is important to consider this modelling exercise as an exploratory analysis showing the potential role of various levels of endogenous boosting on the projected pattern of $\mathrm{HZ}$ incidence after varicella vaccination.

\section{Conclusions}

In a VZV dynamic transmission model, assumptions on relative weighting of exogenous and endogenous boosting effects may have an important and varied impact on the predicted $\mathrm{HZ}$ burden following introduction of childhood varicella vaccination. The HZ burden in the general population is projected to decrease for all boosting scenarios, but a temporary increase in $\mathrm{HZ}$ precedes this effect when exogenous boosting alone is considered. This predicted increase in HZ is markedly reduced even when endogenous boosting is assumed to have a small weight. Endogenous boosting could therefore partly explain divergence between real-world evidence on $\mathrm{HZ}$ burden in countries utilizing childhood varicella vaccination and model projections based on exogenous-only boosting assumption. A safe and effective Varicella vaccine seems to offer the greatest promise controlling even long-term issues caused by this virus.

\section{Additional file}

Additional file 1: Highlights / Patient Focus summarizes the content of the study in a form that could be shared with patients by healthcare professionals. (DOCX $13 \mathrm{~kb})$

\section{Abbreviations}

AIC: Akaike information criterion; BIC: Bayesian information criterion; CMI: Cell-mediated immunity; Endo: Endogenous; Exo: Exogenous; FOl: Force of infection; HZ: Herpes zoster; INSEE: National Institute of Statistics and Economic Studies (Institut national de la statistique et des études économiques); MMR: Measles, mumps and rubella; MMRV: Measles, mumps, rubella, and varicella; RW: Routine (childhood) varicella vaccination; VZV: Varicella-zoster virus; WHO: World Health Organization

\section{Acknowledgements}

The authors would like to thank Iris Depaz for her input and preliminary work during the initiation of this study (she was then employed by GSK, Medical Affairs, Wavre, Belgium).

The Authors would like to thank Business \& Decision Life Sciences platform for editorial assistance and manuscript coordination, on behalf of GSK. Jonathan Ghesquiere coordinated manuscript development and editorial support. The authors also thank Athanasia Benekou (Business \& Decision Life Sciences, on behalf of GSK) for providing medical writing support.

\section{Funding}

GlaxoSmithKline Biologicals SA was the funding source and was involved in all stages of the study conduct and analysis (HO-15-15940). GlaxoSmithKline Biologicals SA also funded all costs associated with the development and the publishing of the present manuscript.

Availability of data and materials

All data used in this study are presented in the manuscript, references to the original material are provided. Please contact the corresponding author shall you require any additional information.

\section{Authors' contributions}

All authors participated to the design of the study and interpretation of the results. $\mathrm{KH}, \mathrm{CS}, \mathrm{PB}, \mathrm{AAG}, \mathrm{MB}$ and $\mathrm{PW}$ participated to the data generation. $\mathrm{KH}$ and CS performed the analysis. BB and SC provided substantial scientific content on the study original idea, coordination with experts, interpretation 
of the results and contribute directly to the manuscript writing and review. All authors reviewed and approved the submitted manuscript.

\section{Ethics approval and consent to participate}

Not applicable for modelling studies.

\section{Consent for publication}

Not applicable.

\section{Competing interests}

$\mathrm{CS}, \mathrm{BB}$, and SC are employed by the GSK group of companies and hold shares in the GSK group of companies as part of their employee remuneration. KH was employed by the GSK group of companies and holds shares as part of her employee remuneration. PW and MB have nothing to disclose. PB reports a grant from the Center for Diseases Control (CCM) in Italy for a project dealing with the disease burden of herpes zoster. AAG reports grants from $\mathrm{NIH}$, personal fees from Merck and the GSK group of companies, and lab support from Merck, outside of the submitted work.

\section{Publisher's Note}

Springer Nature remains neutral with regard to jurisdictional claims in published maps and institutional affiliations.

\begin{abstract}
Author details
'GSK Vaccines, Value Evidence, Wavre, Belgium. ${ }^{2}$ University of Florence, Health Sciences, Florence, Italy. ${ }^{3}$ Columbia University, Pediatrics, New York, NY, USA. ${ }^{4}$ GSK Vaccines, Medical Affairs, Wavre, Belgium. ${ }^{5}$ GSK, Vaccines R\&D, Wavre, Belgium. ${ }^{6}$ Paediatrics and Child Health, University of Sydney, Sydney, Australia. ${ }^{7}$ Department of Experimental Virology, University Hospital Jena, Jena, Germany. ${ }^{8}$ Present address: Bayer AG, Epidemiology, Medical Affairs and Pharmacovigilance, Berlin, Germany.
\end{abstract}

\section{Received: 26 July 2018 Accepted: 29 January 2019} Published online: 06 February 2019

\section{References}

1. Arvin AM. Varicella-zoster virus. Clin Microbiol Rev. 1996:9:361-81.

2. Heininger U, Seward JF. Varicella. Lancet. 2006;368:1365-76.

3. Centers for Disease and Prevention: Epidemiology and Prevention of Vaccine-Preventable Diseases. Varicella. The Pink Book (12th Edition). Accessed 28 Aug 2017. Available at https://www.cdc.gov/vaccines/pubs/ pinkbook/downloads/varicella.pdf

4. European Centre for Disease Prevention and Control: Varicella Vaccination in the European Eunion. https://ecdc.europa.eu/sites/portal/files/media/en/ publications/Publications/Varicella-Guidance-2015.pdf

5. World Health Organization: Immunization, Vaccines and Biologicals: Varicella http://www.who.int/immunization/diseases/varicella/en/.

6. Bonmarin I, Bakao N, Seringe E et al. Epidemiologie de varicelle en France. BEH. 2005; [8]: 30-31.

7. World Health Organization: Systematic review of available evidence on effectivenes and duration of protection of varicella vaccines. http://www. who.int/immunization/sage/meetings/2014/april/4_Systematic_review_on_ effectiveness_and_duration_of_protection_of_varicella_vaccines.pdf

8. WHO. Position paper: varicella and herpes zoster vaccines: WHO. Wkly Epidemiol Rec. 2014;89:265-87.

9. Ramet J, Weil-Olivier C, Sedlak W. Is Europe ready to embrace a policy of universal varicella vaccination? Int J Clin Pract. 2005;59:1326-33.

10. Rentier B, Gershon AA. Consensus: varicella vaccination of healthy children-a challenge for Europe. Pediatr Infect Dis J. 2004:23:379-89.

11. Seward JF, Watson BM, Peterson $C L$, et al. Varicella disease after introduction of varicella vaccine in the United States, 1995-2000. JAMA. 2002;287:606-11.

12. Siedler $A$, Arndt $U$. Impact of the routine varicella vaccination programme on varicella epidemiology in Germany. Euro Surveill. 2010. https://doi.org/ 10.2807/ese.15.13.19530-en

13. Wutzler $P$, Bonanni $P$, Burgess $M$, et al. Varicella vaccination - the global experience. Expert Rev Vaccines. 2017:16:833-43.

14. Bonanni P, Breuer J, Gershon A, et al. Varicella vaccination in Europetaking the practical approach. BMC Med. 2009. https://doi.org/10.1186/ 1741-7015-7-26

15. Bialek SR, Perella D, Zhang J, et al. Impact of a routine two-dose varicella vaccination program on varicella epidemiology. Pediatrics. 2013;132:e1134-40.
16. Hales CM, Harpaz R, Joesoef MR, et al. Examination of links between herpes zoster incidence and childhood varicella vaccination. Ann Intern Med. 2013;159:739-45.

17. Hope-Simpson RE. The nature of herpes zoster: a long-term study and a new hypothesis. Proc R Soc Med. 1965;58:9-20.

18. Gershon AA, LaRussa P, Steinberg S, et al. The protective effect of immunologic boosting against zoster: an analysis in leukemic children who were vaccinated against chickenpox. J Infect Dis. 1996;173:450-3.

19. Oxman MN. Herpes zoster pathogenesis and cell-mediated immunity and immunosenescence. J Am Osteopath Assoc. 2009;109:S13-7.

20. Brisson M, Edmunds WJ, Gay NJ, et al. Modelling the impact of immunization on the epidemiology of varicella zoster virus. Epidemiol Infect. 2000;125:651-69.

21. Russell ML, Schopflocher DP, Svenson L, et al. Secular trends in the epidemiology of shingles in Alberta. Epidemiol Infect. 2007;135:908-13.

22. Tanuseputro P, Zagorski B, Chan KJ, et al. Population-based incidence of herpes zoster after introduction of a publicly funded varicella vaccination program. Vaccine. 2011;29:8580-4.

23. Stein $\mathrm{M}$, Cohen $\mathrm{R}$, Bromberg $\mathrm{M}$, et al. Herpes zoster in a partially vaccinated pediatric population in Central Israel. Pediatr Infect Dis J. 2012;31:906-9.

24. Gil Pietro R, Walter S, Gonzales Escada A, et al. Different vaccination strategies in Spain and its impact on severe varicella and zoster. Vaccine. 2014:32:277-83.

25. Mullooly JP, Riedlinger K, Chun C, et al. Incidence of herpes zoster, 1997-2002. Epidemiol Infect. 2005:133:245-53.

26. Leung J, Harpaz R, Molinari NA, et al. Herpes zoster incidence among insured persons in the United States, 1993-2006: evaluation of impact of varicella vaccination. Clin Infect Dis. 2011:52:332-40.

27. Civen R, Chaves SS, Jumaan A, et al. The incidence and clinical characteristics of herpes zoster among children and adolescents after implementation of varicella vaccination. Pediatr Infect Dis J. 2009;28:954-9.

28. Jumaan $\mathrm{AO}, \mathrm{Yu} \mathrm{O}$, Jackson LA, et al. Incidence of herpes zoster, before and after varicella-vaccination-associated decreases in the incidence of varicella, 1992-2002. J Infect Dis. 2005;191:2002-7.

29. Weinmann S, Chun C, Schmid DS, et al. Incidence and clinical characteristics of herpes zoster among children in the varicella vaccine era, 2005-2009. J Infect Dis. 2013;208:1859-68.

30. Heywood AE, Wang $H$, Macartney KK, et al. Varicella and herpes zoster hospitalizations before and after implementation of one dose varicella vaccination in Australia: an ecological study. Bull World Health Organ. 2014. 92:593-604

31. Siedler A, Dettmann M. Hospitalization with varicella and shingles before and after introduction of childhood varicella vaccination in Germany. Hum Vaccin Immunother. 2014;10:3594-600.

32. Kawai $K$, Yawn BP, Wollan $P$, et al. Increasing incidence of herpes zoster over a 60-year period from a population-based study. Clin Infect Dis. 2016;63:221-6.

33. Harpaz R. The impact of the U.S. Varicella Vaccination Program on the incidence of herpes zoster. https://stacks.cdc.gov/view/cdc/58913/cdc_ 58913 DS1.pdf?download-document-submit=Download.

34. Ogunjimi B, Van DP, Beutels P. Herpes zoster risk reduction through exposure to chickenpox patients: a systematic multidisciplinary review. PLoS One. 2013;8:e66485

35. Brisson M, Melkonyan G, Drolet $\mathrm{M}$, et al. Modeling the impact of one- and two-dose varicella vaccination on the epidemiology of varicella and zoster. Vaccine. 2010:28:3385-97.

36. Bilcke J, van Hoek AJ, Beutels P. Childhood varicella-zoster virus vaccination in Belgium: cost-effective only in the long run or without exogenous boosting? Hum Vaccin Immunother. 2013;9:812-22.

37. Cohrs RJ, Mehta SK, Schmid DS, et al. Asymptomatic reactivation and shed of infectious varicella zoster virus in astronauts. J Med Virol. 2008;80:1116-22

38. Ogunjimi $B$, Theeten $H$, Hens $N$, et al. Serology indicates cytomegalovirus infection is associated with varicella zoster virus reactivation. J Med Virol. 2014;86:812-9.

39. Schunemann S, Mainka C, Wolff MH. Subclinical reactivation of varicellazoster virus in immunocompromised and immunocompetent individuals. Intervirology. 1998:41:98-102.

40. Birlea M, Arendt G, Orhan E, et al. Subclinical reactivation of varicella zoster virus in all stages of HIV infection. J Neurol Sci. 2011:304:22-4.

41. Gershon A, Chen J, Davis L, et al. Latency of varicella zoster virus in dorsal root, cranial, and enteric ganglia in vaccinated children. Trans Am Clin Climatol Assoc. 2012;123:17-35. 
42. Poletti P, Melegaro A, Ajelli M, et al. Perspectives on the impact of varicella immunization on herpes zoster. A model-based evaluation from three European countries. PLoS One. 2013;8:e60732.

43. Ouwens MJ, Littlewood K, Sauboin C, et al. The impact of 2-dose routine measles, mumps, rubella, and varicella vaccination in France on the epidemiology of varicella and zoster using a dynamic model with an empirical contact matrix. Clin Ther. 2015;37:816-29.

44. Oxman MN, Levin MJ. Vaccination against herpes zoster and Postherpetic neuralgia. J Infect Dis. 2008;197:S228-36.

45. Prymula R, Bergsaker MR, Esposito S, et al. Protection against varicella with two doses of combined measles-mumps-rubella-varicella cavvine versus one dose of monovalent vaccine: a multicentre, observer-blind, randomised, controlled trial. Lancet. 2014;383:1313-24.

46. Ogunjimi B, Willem L, Beutels P, et al. Integrating between-host transmission and within-host immunity to analyze the impact of varicella vaccination on zoster. elife. 2015. https://doi.org/10.7554/elife.07116.

47. Gershon AA, Gershon MD, Breuer J, et al. Advances in the understanding of the pathogenesis and epidemiology of herpes zoster. J Clin Virol. 2010;48:S2-7.

48. Marinelli I, van Lier A, de Melker $\mathrm{H}$, et al. Estimation of age-specific rates of reactivation and immune boosting of the varicella zoster virus. Epidemics. 2017:19:1-12.

49. Hales CM, Harpaz R, Ortega-Sanchez I, et al. Update on recommendations for use of herpes zoster vaccine. MMWR Morb Mortal Wkly Rep. 2014;63:729-31.

50. Lal H, Cunningham AL, Godeaux O, et al. Efficacy of an adjuvanted herpes zoster subunit vaccine in older adults. N Engl J Med. 2015;372:2087-96.

51. van Hoek AJ, Melegaro A, Zagheni E, et al. Modelling the impact of a combined varicella and zoster vaccination programme on the epidemiology of varicella zoster virus in England. Vaccine. 2011;29:2411-20.

52. Kawai K, Yawn BP. Risk factors for herpes zoster: a systematic review and meta-analysis. Mayo Clin Proc. 2017;92:1806-21.

53. Korostil IA, Regan DG. Varicella-zoster virus in Perth, Western Australia: seasonality and reactivation. PLoS One. 2016;11:e0151319.

54. Institut National de la Statistique et des etudes Economiques: Estimation de la population au 1 er janvier 2016, Series par region, departement, sexe et Bge de 1975 a 2016. INSEE. Available at https:/www.insee.fr/fr/statistiques/ 1893198

55. Silverman B, Hemo B, Friedman N. Varicella vaccine effectiveness in a israeli health maintenance organisation. Abstract presented at: 27th Annual Meeting of the European Society for Pediatric Infectious Diseases; Brussels, Belgium. 2009.

Ready to submit your research? Choose BMC and benefit from:

- fast, convenient online submission

- thorough peer review by experienced researchers in your field

- rapid publication on acceptance

- support for research data, including large and complex data types

- gold Open Access which fosters wider collaboration and increased citations

- maximum visibility for your research: over $100 \mathrm{M}$ website views per year

At BMC, research is always in progress.

Learn more biomedcentral.com/submissions 